\title{
Comigrants and friends: informal networks and the transmission of traditional ecological knowledge among seminomadic pastoralists of Gujarat, India
}

\author{
$\underline{\text { Matthieu Salpeteur }}^{1}$, Hanoz H. R. Patel $^{2}, \underline{\text { José Luis Molina }}^{3}, \underline{\text { Andrea L. Balbo }}^{4}, \underline{\text { Xavier Rubio-Campillo }}^{5}, \underline{\text { Victoria Reves-García }}^{1,6}$ \\ and Marco Madella 6,7
}

\begin{abstract}
Previous research has shown that social organization may affect the distribution of traditional ecological knowledge (TEK) within local communities of natural resource users in multiple ways. However, in this line of research the potential role of informal relationships has mostly been overlooked. In this article, we contribute toward filling this research gap by studying how two types of informal relationships, namely migration partnership and friendship, affect the distribution of TEK within a community of seminomadic pastoralists from the Kutch area, Gujarat, India. Using social network analysis, we map three networks, migration, men friendship, and women friendship, and compare with similarity-based quantitative approaches the clusters extracted from these networks in relation to four domains of TEK: knowledge about soils, about ethnoveterinary practices, about sheep breeds, and in ethnobotany. Our results show that (1) migration clusters are associated to significant variations in three TEK domains, while (2) friendship clusters are associated to minor variations. We relate these results to the importance of common practical experiences involved by joint migration. Moreover, kin relations are shown to strongly underlie friendship and migration relations, and as such appear as a potential driver of the dynamics of the local TEK system. We conclude by advocating for a better inclusion of such informal relationships in future research on local TEK dynamics, following recent developments in studies on natural resource governance.
\end{abstract}

Key Words: friendship; India; informal relationships; migration; pastoralists; Rabari; social network analysis; social organization; traditional ecological knowledge

\section{INTRODUCTION}

The implication of multiple stakeholders, from local users to institutional bodies, in landscape and natural resources management is increasingly being recognized as needful for successful governance, as illustrated by the fast spread and adoption of the concept of adaptive comanagement (Armitage et al. 2008). The adaptive comanagement approach explicitly takes into account the dynamic state of ecosystems (Holling 1973), which implies some degree of unpredictability in management (Berkes et al. 2000) and, as such, requires constant input from multiple sources about the state of the natural resources. In this perspective, traditional ecological knowledge (TEK), defined here as "a cumulative body of knowledge, practice and belief, evolving by adaptive processes and handed down through generations by cultural transmission, about the relation of living beings (including humans) with one another and with their environment" (Berkes et al. 2000:1252), has been shown to be critically important for adaptive comanagement because it provides a different and complementary understanding of ecosystems to Western science (Gadgil et al. 1993, Berkes and Turner 2006). For instance, recent research has demonstrated the relevance of pastoralists' knowledge to assess the local ecological impacts of climate change (Marin 2010, Joshi et al. 2013). Such information becomes critical when local ecological data are not available or not precise enough to interpret global climatological models. In this line, understanding the dynamics of TEK systems and the patterns of TEK distribution across local communities appears as an important challenge in the quest for achieving adaptive comanagement. Here, we contribute to research aiming to understand variation in TEK systems by studying how the social organization of local communities affects the distribution and transmission of TEK.

Variations of TEK across communities of resource users have been studied from different perspectives. First, some researchers have explored the influence of social roles related to individual characteristics in shaping TEK variations at the community level. Some of the individual characteristics studied have been gender (Camou-Guerrero et al. 2008), age (Begossi et al. 2002), formal education (Zarger 2002), and market integration (Reyes-García et al. 2005), all characteristics that implicitly encompass social organization. A second line of research has explicitly aimed at understanding the role of communities' organizational features in explaining TEK distribution. Such work has examined features pertaining to "social organization" as understood by classical social anthropology, such as kinship. For instance, in a previous publication we have shown that, among the Rabari seminomadic pastoralists of India, kin-based groups (agnatic lineages and segments of lineages) hold differentiated bodies of TEK related to the pastoral activity (Salpeteur et al. 2015). Similar results have been found for other geographical areas, cultural groups, and domains of knowledge (Boster 1986, Labeyrie et al. 2014).

\footnotetext{
${ }^{1}$ Institut de Ciència i Tecnologia Ambientals, Universitat Autònoma de Barcelona, Spain, ${ }^{2}$ The Maharaja Sayajirao University of Baroda, Vadodara, Gujarat, India, ${ }^{3}$ Departament d'Antropologia, Universitat Autònoma de Barcelona, Spain, ${ }^{4}$ Research Group Climate Change and Security (CLISEC), KlimaCampus, Center for Earth System Research and Sustainability (CEN), University of Hamburg, Germany. * Work partially done while affiliated to Complexity and Socio-Ecological dynamics (CaSEs), Institució Milà i Fontanals, Spanish National Research Council (IMFCSIC), C/Egipciaques 15, 08001 Barcelona, Spain, ${ }^{5}$ Barcelona Supercomputing Center (BSC), Barcelona, Spain, ${ }^{6}$ Institució Catalana de Recerca i Estudis Avançats (ICREA), Barcelona, Spain, ${ }^{7}$ Complexity and Socioecological Dynamics (CaSEs) Universitat Pompeu Fabra and IMF-CSIC, Barcelona, Spain
} 
Occupation-related groups, i.e., groups involved in differentiated uses of resources, have also been shown to hold differentiated knowledge. For instance, Ghimire et al. (2005) show that different groups of plants collectors from Nepal hold different ethnobotanical knowledge. Finally, using social networks analysis, a recent body of research has focused on the relational patterns related to TEK transmission. In this line, both patterns of interindividual exchanges and an individuals' position in the resulting networks can explain differentiated TEK among individuals, as it has been shown in relation to herbal remedies knowledge in Mexico (Hopkins 2011), or local landraces knowledge in the Iberian peninsula (Calvet-Mir et al. 2012, ReyesGarcía et al. 2013), or individuals making use of the same gear for natural resource extraction (Crona and Bodin 2006, 2011).

\section{Social organization and TEK transmission}

The ways in which the organizational features of a community may affect the transmission and distribution of TEK are multiple and complex. We propose here to ground our conceptual framework on the distinction between theoretical and practical knowledge (skills, know-how) commonly used in anthropology of knowledge (Barth 2002) and in TEK studies in particular (Ohmagari and Berkes 1997, Reyes-García et al. 2007). Following this distinction, the social organization of a community, and the patterned relations and interactions that arise from this organization, may affect TEK transmission through two main pathways, that we will examine in this article. First, because social organization underlies the emergence of clusters of individuals who are engaged in differentiated activities and uses of natural resources, social organization may favor the development of common experiential knowledge and skills among members of these groups. A potential pathway for the development of such common experiential knowledge is repeated contacts with the natural resources, which may differ between groups engaged in different activities (Ghimire et al. 2005). Second, to some extent, the social organization frames the patterns of interindividual exchanges within the community, both by favoring and hindering some specific relationships, through cultural barriers, for example (Leclerc and Coppens d'Eeckenbrugge 2011, Labeyrie et al. 2014)). Therefore, social organization is also likely to favor the patterned spread of theoretical knowledge, through verbal exchanges, or of knowledge associated to exchanged items, such as seeds. In this regard, a body of research focusing on natural resource management has shown that fishers are more likely to exchange information about the state of natural resources with closely related individuals, such as friends and kin (Aswani 2002, Ramirez-Sanchez and Pinkerton 2009), or with individuals using the same fishing gear (Crona and Bodin 2006, 2011), all results suggesting that such relationships may also favor TEK exchanges in different contexts. Thus, these two facets of social organization, related to theoretical and practical knowledge, are intertwined and likely to shape transmission and distribution of TEK within a given community in different ways. Individuals clustering in specific collectives are likely to develop common experiences within these groups, while individuals who engage in interindividual exchanges are likely to share theoretical knowledge. But the two dimensions are not exclusive because individuals engaged in a similar productive activity are also more likely to exchange knowledge about the resources, while interindividual privileged connections may also result in the implementation of common activities.
We aim at exploring the role of different types of informal organizational features on the distribution of TEK related to the pastoral activity, through a case study focusing on a community of seminomadic pastoralists from Gujarat, India. In a previous publication deriving from this same research (Salpeteur et al. 2015), we explored the role of patrilineal descent groups on the intra-cultural distribution of TEK within this community. We showed that, for some of the four domains of TEK studied (see details below), the agnatic lineages and segments of lineages, including the women related to these lineages through marriage, held significantly different bodies of knowledge, and that these variations were not due to other factors such as gender, age, or experience. One of our hypotheses to explain these results related to the social organization of migration: as within the Rabari kinrelated people migrate together, the occupation-related experience and knowledge is shared within agnatic kin groups during the migration cycle. Here, we build on this finding by including two new dimensions of the social organization of the local community. We first include the migration groups, informal collectives that are created when shepherds migrate and that constitute the basis of everyday life throughout all the migration cycle. By studying to what extent such groupings may affect local TEK transmission processes, we specifically aim at testing the robustness of our previous results. Second, we include friendship networks, a web of informal relations considered here as a type of informal social organization. These two components of the social organization relate to strong relationships, our specific objective being to analyze the role of these relationships in shaping the variations of TEK across the studied community.

Our work also offers a methodological contribution. Previous researchers have explored the relation between social networks structure and TEK distribution by focusing on networks directly related to the studied TEK: seed exchange networks and ethnobotanical knowledge (Hopkins 2011, Calvet-Mir et al. 2012, Reyes-García et al. 2013), herbal remedy inquiries and ethnomedicinal knowledge (Hopkins 2011), exchange of information related to fishing activities and TEK related to coastal ecosystems (Crona and Bodin 2006). Here, we do not study networks specifically related to knowledge exchanges; rather, we focus on strong social ties that potentially favor TEK exchanges. By comparing TEK across clusters extracted from these networks, we aim at analyzing how such clusters, and, as a result, such informal networks, shape the transmission and distribution of TEK across members of the studied community.

\section{METHODS}

\section{Case study setting}

The Rabari community (also called Raika) represents the most important pastoralist group in contemporary India, with a population ranging from five to six hundred thousand peoples (Srivastava 1991, Agrawal 1992), mainly found in Rajasthan and Gujarat, and across northwestern and central India (Prévot 2007). Since the mid-20th century, a number of sociopolitical events and processes such as the partition of India and Pakistan, the Green revolution (Choksi and Dyer 1996), or the 2001 Kutch earthquake, have resulted in increasing difficulties to pursue nomadic pastoralism, leading to important transformations of mobility patterns and strong occupational shifts within the Rabari (Salpeteur et al. 2016). A growing demand for formal education has also increased during the last two decades, constituting a 
strong internal driver for change (Dyer 2008). Thus, today, the Rabari community displays an important diversity in terms of occupation, with the adoption of sedentary occupations becoming dominant in northern and southern Gujarat. Camel keeping, which was the primary occupation of this community (Srivastava 1991, Prévot 2007), is only pursued by a small sector of the population (Bharwada and Mahajan 2010), while sheep and goat keeping is dominant in Kutch and Saurashtra. In Kutch district, our study area, highly diverse ways to keep ovicaprids can be observed. Although a few individuals remain all year round within a delimited area, most shepherds are seminomadic, following seasonal cycles and moving across different territories: in Kutch only, Gujarat from west to east and back, or within delimited regions in central Indian states (Maharashtra, Chhattisgarh).

\section{Social organization and informal relationships among Rabari}

Among the Rabari pastoralists, the society has different levels of organization. The overall community is divided into subgroups attached to specific territories (paragana), which display minor cultural differences regarding the ritual calendar or external signs of belonging. Besides these divisions, the whole community is divided into patrilineal descent groups: clans (shak), whose members can be found across different states and paraganas, and lineages and segments of lineages (vaas), which operate at the village level and constitute the most meaningful level of social organization in daily life of pastoralists. In this study, we focus on segments of lineages.

As with most nomadic societies (Mauss 1979), the Rabari have a specific social organization associated to migration. During the nomadic phase of the yearly cycle, spanning from 2 to 12 months, the Rabari households cluster in groups called dang. The size of a dang varies from two to eight households depending on a wide set of factors, such as the density of farming areas to be crossed, the risks of harassment, the potential benefits of pooling the labor or the costs related to the pastoral activity, although one of the most defining factors is the distance to be travelled: the greater the distance, the bigger the dang. These migration groups are relatively stable from one year to the other, and in our study area, they mostly cluster households of close relatives: a father and his sons, some brothers and brothers-in-law, and the like. As such, dangs can be seen as resulting from the coresidence rules that characterize, during mobile phases, agnatic lineages among this community. However, the association of households into migration groups may go beyond kinship, such as the production strategies of shepherds and the preference for specific migration areas.

Friendship, in this study, is somewhat equivalent to the notion of "good friend" in Western countries. Such relations are based on a deep mutual understanding and regular contacts and entails support and mutual help. In the study area, friends are referred to as bhai or bhen (brother and sister), which suggests a closer relation than the common notion of friendship found in Gujarat (mistra). Personal and voluntary, friendship among the Rabari is, however, framed to some extent by gender relations: intergender friendship relations are almost nonexistent (as also noted by Allan 1989). Friends can be kin-related individuals or not.

\section{Data collection}

Fieldwork in the Gujarat state was carried out during one year, from February 2012 to February 2013. We first conducted an exploratory survey across North Gujarat, the Saurashtra peninsula, and the Kutch area (Fig. 1) to monitor the current state of pastoralist productive activities and get primary data about migration patterns and current trends of change. We then focused on the Anjar taluka, a subdivision of the Kutch district, where the highest diversity of nomadic pastoral activities was observed and that hosts the Dhebar Rabari community, one of the Rabari paragana found in Kutch. After receiving agreement from the Dhebar community council and the village authorities, we conducted an in-depth survey in the Mindiyala village and across the whole taluka.

Fig. 1. Map of the study area. Source: Adapted from http://dmaps.com and Gujarat state map, Government of Gujarat.

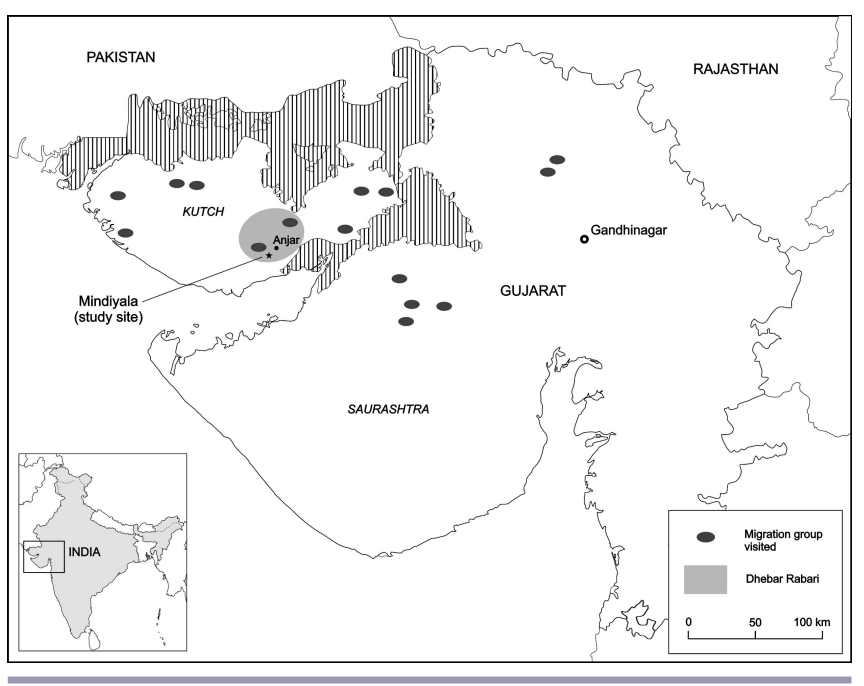

Qualitative data and sampling

We conducted exploratory and focus group interviews as well as semistructured interviews with an extensive range of informants selected using the snowballing technique (Bernard 2006). Before each interview, we obtained free, prior, and informed consent. We also conducted participant observation with active pastoralists, accompanying them on daily walks and during the migration process. Data collection was carried out both in villages and in migratory groups. Overall, we visited 35 migrating groups, some of them only once, some of them repeatedly. The qualitative data collected referred both to social organization and to TEK. Qualitative data on social organization covered both the time when individuals were migrating and the time when they were settled, and included the kinship system and the formal and informal relations in which people engage during their daily life. Qualitative data on TEK related to pastoral activities, by identifying domains of knowledge and ways of transmission of different types of knowledge. We used these data to build a questionnaire for systematic data collection. Several versions of the questionnaire were tested in other villages to ensure that our questions captured different levels of knowledge. We used census data from the village of Mindiyala to select a sample of informants stratified across gender and patrilineal descent groups 
Table 1. Description of the variables included in this study.

\begin{tabular}{|c|c|c|c|c|c|c|c|}
\hline \multirow[t]{3}{*}{ Individual variables } & \multirow[t]{3}{*}{ Description } & \multicolumn{2}{|c|}{ Migration clusters } & \multicolumn{4}{|c|}{ Friendship clusters } \\
\hline & & \multirow[b]{2}{*}{$\%$} & \multirow[b]{2}{*}{$\mathrm{n}$} & \multicolumn{2}{|c|}{ Men } & \multicolumn{2}{|c|}{ Women } \\
\hline & & & & $\%$ & $\mathrm{n}$ & $\%$ & $\mathrm{n}$ \\
\hline Gender & $(\%$ of men $)$ & 57.4 & & & & & \\
\hline \multirow{5}{*}{ Age groups } & (4 categories) & & & & & & \\
\hline & young $(0-20)$ & & 3 & & 2 & & 0 \\
\hline & middle $(21-40)$ & & 24 & & 27 & & 9 \\
\hline & mature $(41-60)$ & & 16 & & 21 & & 16 \\
\hline & old (61 and more) & & 11 & & 8 & & 15 \\
\hline \multirow{5}{*}{$\begin{array}{l}\text { Schooling } \\
\text { Occupation change delay }\end{array}$} & Did the individual go to school? (Yes/No, $\%$ of Yes) & 24.07 & & 31.03 & & 0.1 & \\
\hline & 3 categories (only applied to retired shepherds) & & & & & & \\
\hline & short $=0-4$ yrs & & 11 & & 13 & & 5 \\
\hline & mean $=5-9$ yrs & & 13 & & 9 & & 8 \\
\hline & long $=10+\mathrm{yrs}$ & & 15 & & 15 & & 17 \\
\hline
\end{tabular}

(segments of lineages) composition. Once the composition of the sample was set, participants were randomly contacted and eventually included in the sample according to their willingness to participate and their availability at the time of the survey. We conducted 164 questionnaires from which we removed 29 for incompleteness or incoherence of answers, obtaining a final sample of 135 interviews. This sample is slightly smaller than the one used in the previous study (Salpeteur et al. 2015: 164 individuals) because some informants did not provide answers to social network questions. Overall, our sample covers 113 households, about $25 \%$ of the estimated 450 households in the village. The questionnaire was structured in three parts: (a) individual characteristics (see Table 1), (b) social network data, and (c) TEK questions.

\section{Social network data}

Social relations related to migration and friendship were collected through social network analysis methods. We used a different name generator to capture each of the networks. To collect migration ties, we asked, "Can you give us the names of the persons from this village with whom you are migrating nowadays or have migrated in the past?" To collect friendship ties, we asked, "Can you give us the names of the persons from this village you consider to be your good friends?" For each alter (i.e., individual network member) cited, we recorded the alter's agnatic group and the name of the husband or wife of the alter. We gave no limit to interviewees in relation to the number of names to be listed.

\section{TEK questions}

The survey included questions related to four domains of knowledge:

1. Soils classification (TEK_soils): Rabari pastoralists refer to soils and their associated vegetation using a scale based on an analogy with food tastes: soils can be either mitho (sweet), kharo (salty), or moro (without specific taste). These categories are not to be equated with the degree of salinity of soils measured by pedologists. Salty and sweet areas sustain different types of vegetation, but both are seen as having good nutritional value for small ruminants, contrary to moro areas.

2. Ethnoveterinary (TEK_tado): Besides chemical drugs (Geerlings 2001), tado, the iron-rod cauterization (Singh et al. 2014), is widely used as a veterinary cure among Rabari pastoralists. It consists in burning the skin of the sick animal with red-hot iron tools; the design to be drawn and the part of the body to be burnt are disease-specific.

3. Sheep breeds (TEK_breeds): Breeds are chosen according to a set of characteristics (resistance to drought and migration, wool and meat quality, reproduction rates and success), in accordance with production objectives of each shepherd.

4. Ethnobotany (TEK_botany): plants with medicinal and veterinary properties are widespread and widely used in daily life by the Rabari shepherds. We selected a subset of plant species and associated medical uses (one use per plant), and built yes/no questions in the following form: Does this plant cure this ailment?

We selected 11 questions on soils, four on breeds, and nine on ethnobotany. The questions were either multiple choice or binary. To proxy tado knowledge, we asked informants to free list all of the diseases they knew to be cured using tado and to describe the part of the body and the design to be burned for the diseases listed. Further information about these questions can be found in the supplements of Salpeteur et al. (2015).

\section{Data analysis: uncovering variations in TEK across social networks}

Clusters in the networks were identified using two methods. We used network graphs to visually identify connected components and to eliminate isolated individuals, e.g., interviewees who did not cite any friends or migration partners during the interview. In the case that connected components were not standing out (male friendship network), we further applied the GirvanNewman algorithm (Girvan and Newman 2002) to identify groups of nodes densely related. Among the clusters thus identified, we selected the ones containing a number of interviewees equal or greater than four for further comparison to keep a sufficient level of significance in statistical analyses while maintaining a maximum number of individuals in our sample. Because the network data collected are not sufficient to draw whole networks, statistics such as centrality and density measures are not relevant here. Primary visualization and assessment of networks was done with NodeXL (Smith et al. 2010), further 
analyses with the igraph package (Csardi and Nepusz 2006) in the R software (R Development Core Team 2011).

To assess TEK variations across groups, we computed analyses that explicitly take into account the similarity of answers between interviewees. Following Labeyrie et al. (2014) and Salpeteur et al. (2015), we used the Jaccard similarity index to measure the distance between individual answers in each of the four domains of knowledge. The distance matrices thus created were then used as the output (or dependent) variable in distance-based multivariate analyses, and were tested against a set of explanatory variables: (a) migration and friendship clusters, (b) kinship groups, and (c) individual characteristics (age, gender, pastoralists experience). These analyses first allowed us to see if the chosen group-related variables (kinship groups, migration, and friendship clusters) were associated to significant variations in TEK (considering each of the four selected domains). Second, by introducing individual characteristics along group-related variables, we were able to estimate the weight of these variables in explaining the overall measured variations. We ran permutational multivariate analyses of variance (PERMANOVA), which function as a multiple linear model. Because this analysis is sequential, using type I sum of squares (Oksanen et al. 2013), we ran analyses placing the variable of interest first (in our case migration or friendship clusters), with a step-wise backward elimination procedure to reach the best-fitting model. We ran separate analyses for each TEK domain, first with migration network data and second with friendship networks. Analyses were done with the packages ade4 (Dray and Dufour 2007) and vegan (Oksanen et al. 2013) in the R software.

\section{RESULTS}

\section{Overall network characteristics}

Interviewees cited an average of 4.51 names of migration partners. The migration network comprised 595 nodes (individuals) and 609 ties (citations), grouped in 69 connected components. From these, we removed the components containing less than four interviewees, obtaining a network subset comprising 196 nodes and 246 ties grouped in 9 connected components, including 54 interviewees (Fig. 2). A prominent feature of this network was that, despite representing data from people in the same village, it was formed by 9 separate components.

Because friendship is a highly gendered relationship within the Rabari, we drew separate friendship networks for men and women. On average, men cited 5.12 good friends whereas women cited 2.85. The initial male friendship network comprised 315 nodes and 399 ties, spread across one main connected component, which was maintained for analysis, and two small isolated components, which we discarded because they contained only one interviewee each. The Girvan-Newman clustering method applied to the main component identified 16 clusters (Fig. 3). From these, we selected the clusters containing at least four interviewees, so our final sample consists of 56 interviewees grouped in 8 clusters (Table 2). The female friendship network comprised 240 nodes and 231 ties spread across 35 connected components. Because these connected components were already standing out, we did not apply any further clustering method. After removing components with less than 4 interviewees, we obtained a final network comprising 106 nodes and 115 ties, with 40 interviewees grouped in 6 clusters (Fig. 4).
Fig. 2. Migration network, displaying nine main connected components extracted from the complete data. Red nodes represent interviewees, squares represent women, and circles men. Note: for noninterviewees, the default shape is a circle when the gender is unknown.

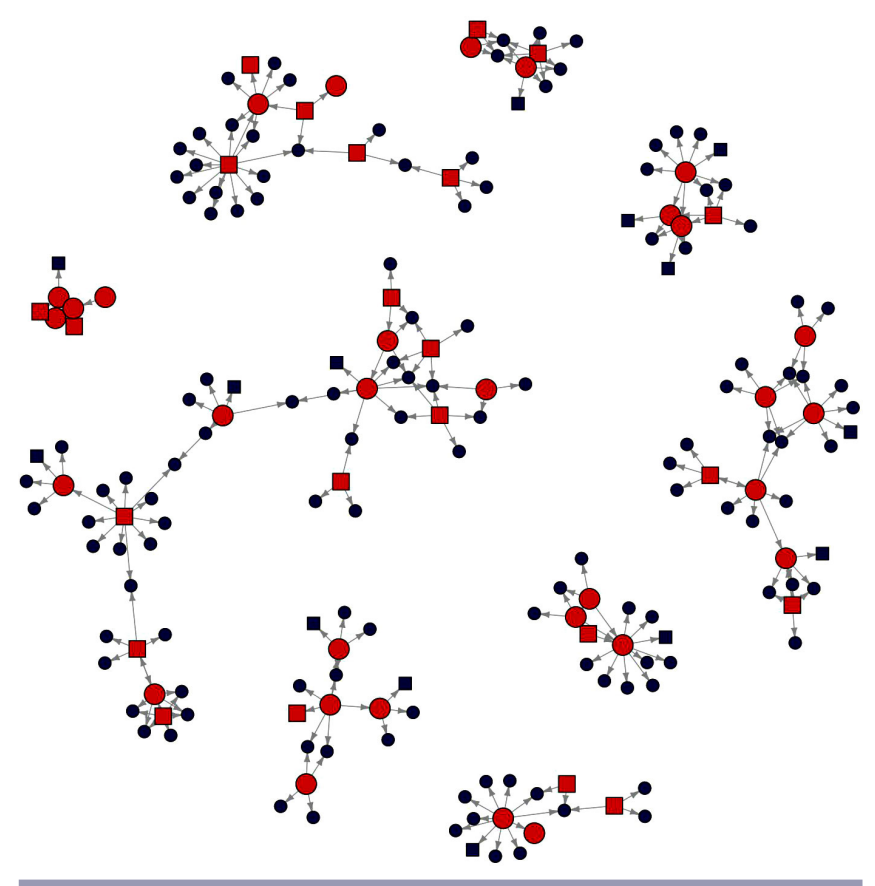

Fig. 3. Male friendship network, displaying 16 main clusters extracted through the Girvan-Newman method (in color). Large nodes represent interviewees, small ones noninterviewees.

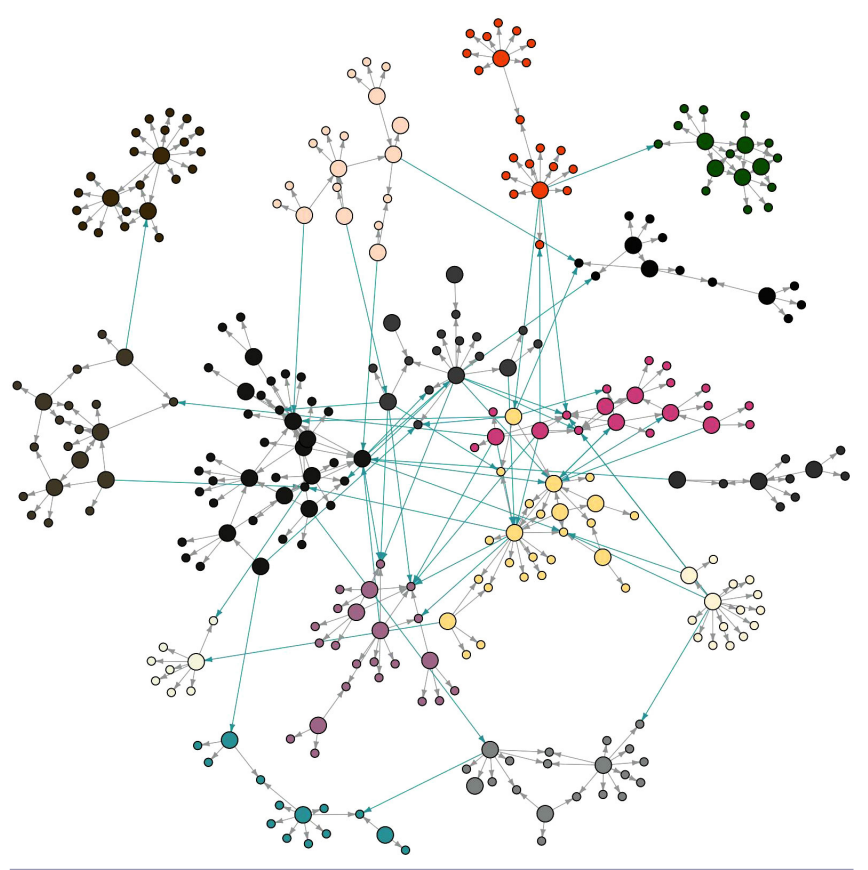


Table 2. Distribution of the population across network clusters (migration and friendship) and individual characteristics.

\begin{tabular}{|c|c|c|c|c|c|c|c|c|c|c|c|c|c|}
\hline \multirow[t]{2}{*}{ Clusters } & \multirow{2}{*}{$\begin{array}{c}\text { Total } \\
\text { number of } \\
\text { nodes }\end{array}$} & \multirow{2}{*}{$\begin{array}{l}\text { Number of } \\
\text { interviewees }\end{array}$} & \multirow{2}{*}{$\begin{array}{c}\text { Gender }(\% \\
\text { of men })\end{array}$} & \multicolumn{4}{|c|}{ Age categories } & \multicolumn{2}{|c|}{ Education } & \multicolumn{4}{|c|}{ Occupation change delay } \\
\hline & & & & Young & Middle & Mature & Old & None & Yes & $\mathrm{N} / \mathrm{A}$ & Short & Mean & Long \\
\hline \multicolumn{14}{|c|}{ Migration clusters } \\
\hline M01 & 16 & 4 & $50.00 \%$ & 0 & 2 & 1 & 1 & 4 & 0 & 3 & 0 & 0 & 1 \\
\hline M02 & 16 & 4 & $75 \%$ & 0 & 2 & 1 & 1 & 4 & 0 & 2 & 0 & 0 & 2 \\
\hline M03 & 7 & 6 & $66.67 \%$ & 0 & 5 & 0 & 1 & 4 & 2 & 5 & 0 & 0 & 1 \\
\hline M06 & 55 & 13 & $46.15 \%$ & 2 & 3 & 4 & 4 & 10 & 3 & 2 & 1 & 6 & 4 \\
\hline M09 & 30 & 7 & $71.43 \%$ & 1 & 5 & 1 & 0 & 3 & 4 & 1 & 4 & 1 & 1 \\
\hline M13 & 17 & 5 & $80 \%$ & 0 & 2 & 1 & 2 & 4 & 1 & 2 & 1 & 2 & 0 \\
\hline M14 & 11 & 4 & $50 \%$ & 0 & 2 & 1 & 1 & 3 & 1 & 0 & 0 & 3 & 1 \\
\hline M22 & 28 & 7 & $28.57 \%$ & 0 & 2 & 4 & 1 & 6 & 1 & 0 & 1 & 1 & 5 \\
\hline M55 & 16 & 4 & $75 \%$ & 0 & 1 & 3 & 0 & 3 & 1 & 0 & 4 & 0 & 0 \\
\hline Total & 196 & 54 & $57.40 \%$ & 3 & 24 & 16 & 11 & 41 & 13 & 15 & 11 & 13 & 15 \\
\hline \multicolumn{14}{|c|}{ Friendship clusters } \\
\hline \multicolumn{14}{|c|}{ Men } \\
\hline FM01 & 23 & 5 & & 0 & 1 & 2 & 2 & 5 & 0 & 1 & 1 & 0 & 3 \\
\hline FM02 & 40 & 12 & & 0 & 10 & 2 & 0 & 8 & 4 & 2 & 3 & 3 & 4 \\
\hline FM04 & 20 & 7 & & 0 & 2 & 3 & 2 & 6 & 1 & 3 & 2 & 1 & 1 \\
\hline FM05 & 17 & 5 & & 0 & 1 & 2 & 2 & 4 & 1 & 3 & 1 & 1 & 0 \\
\hline FM06 & 17 & 5 & & 0 & 1 & 4 & 0 & 4 & 1 & 1 & 3 & 0 & 1 \\
\hline FM07 & 20 & 4 & & 0 & 1 & 2 & 1 & 4 & 0 & 3 & 0 & 1 & 0 \\
\hline FM08 & 25 & 7 & & 0 & 2 & 5 & 0 & 6 & 1 & 3 & 1 & 2 & 1 \\
\hline FM13 & 18 & 7 & & 0 & 5 & 1 & 1 & 3 & 4 & 1 & 2 & 1 & 3 \\
\hline FM14 & 20 & 6 & & 2 & 4 & 0 & 0 & 0 & 6 & 4 & 0 & 0 & 2 \\
\hline Total & 200 & 58 & & 2 & 27 & 21 & 8 & 40 & 18 & 21 & 13 & 9 & 15 \\
\hline \multicolumn{14}{|l|}{ Women } \\
\hline FW02 & 23 & 8 & & 0 & 2 & 2 & 4 & 7 & 1 & 2 & 1 & 2 & 3 \\
\hline FW03 & 15 & 7 & & 0 & 2 & 5 & 0 & 7 & 0 & 1 & 1 & 1 & 4 \\
\hline FW05 & 9 & 4 & & 0 & 1 & 0 & 3 & 4 & 0 & 1 & 2 & 1 & 0 \\
\hline FW08 & 32 & 12 & & 0 & 4 & 5 & 3 & 9 & 3 & 4 & 1 & 2 & 5 \\
\hline FW15 & 14 & 4 & & 0 & 0 & 2 & 2 & 4 & 0 & 0 & 0 & 1 & 3 \\
\hline FW17 & 13 & 5 & & 0 & 0 & 2 & 3 & 5 & 0 & 2 & 0 & 1 & 2 \\
\hline Total & 106 & 40 & & 0 & 9 & 16 & 15 & 36 & 4 & 10 & 5 & 8 & 17 \\
\hline
\end{tabular}

Fig. 4. Female friendship network, displaying six main connected components. Large nodes represent interviewees, small ones noninterviewees.

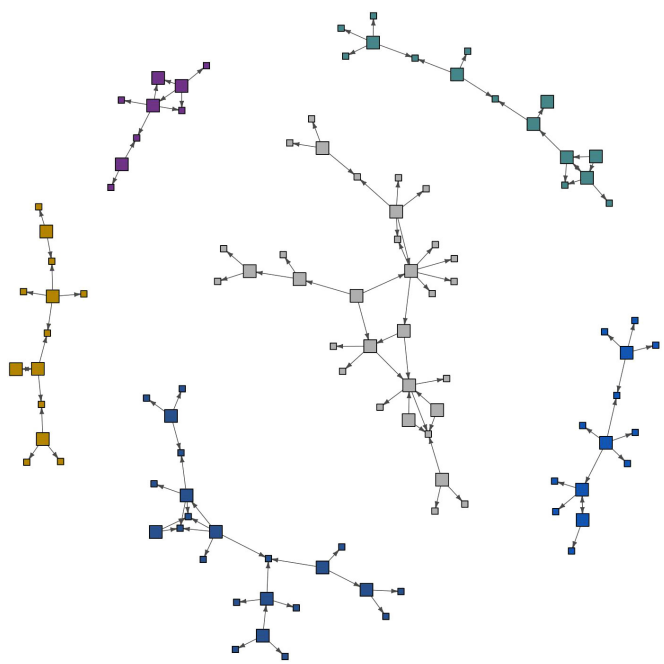

Age and experience, kinship

Migration and male friendship clusters showed a quite high diversity regarding the age of its members, their level of education, or the time spent since the person abandoned the pastoral activity (Table 2). There was no patterned distribution of these three variables across the clusters, with the notable exception of the cluster FM14, uniquely comprising educated individuals, a proportion well above the mean education rate per friendship cluster $(31 \%)$. Female friendship groups displayed the same tendency except for age, where they tended to be more homogeneous: three clusters (FW03, FW15, FW17) were composed of women belonging to close age categories, e.g., middle-aged and mature, mature and old.

The distribution of agnatic groups across the different network clusters (Table 3 ) showed that segments of lineage and migration clusters clearly overlap (Fig. 5): four components were constituted by members of a unique segment of lineage, while the other components clustered members of two to four different segments of lineage. In the case of friendship networks, clusters tended to be more diverse regarding kinship inclusion: in the cluster FM05, for example, each individual belongs to a different segment of lineage. But we observed as well that some clusters are grouping members of only one or two agnatic groups (FM01, FM06, FW03, FW15). 
Table 3. Kinship group inclusion across migration and friendship clusters.

\begin{tabular}{|c|c|c|c|c|c|c|c|c|c|c|c|c|c|c|c|c|c|c|c|c|}
\hline \multirow[t]{2}{*}{ Clusters } & \multirow{2}{*}{$\begin{array}{l}\text { Number of } \\
\text { interviewees }\end{array}$} & \multicolumn{19}{|c|}{ Segments of lineage (kinship groups) } \\
\hline & & $\mathrm{BG}$ & BJ & DV & JS & $\mathrm{JL}$ & $\mathrm{JK}$ & $\mathrm{KC}$ & KT & MO & NK & PT & RG & RM & $\mathrm{RN}$ & SH & SJ & SR & $\mathrm{TJ}$ & VR \\
\hline \multicolumn{21}{|c|}{ Migration clusters } \\
\hline M01 & 4 & & & & & 4 & & & & & & & & & & & & & & \\
\hline M02 & 4 & & & & & & 4 & & & & & & & & & & & & & \\
\hline M03 & 6 & & & & & & & & & & & & & & & & 6 & & & \\
\hline M06 & 13 & & & & & & & & & & 6 & & 7 & & & & & & & \\
\hline M09 & 7 & & & 4 & & & 2 & & & & & 1 & & & & & & & & \\
\hline M13 & 5 & & & & & & & & & & & & 2 & & & & & & 3 & \\
\hline M14 & 4 & & & 4 & & & & & & & & & & & & & & & & \\
\hline M22 & 7 & & & & & & & & & & & 6 & & & 1 & & & & & \\
\hline M55 & 4 & & & & & & & & & & & & & 4 & & & & & & \\
\hline Total & 54 & & & 8 & & 4 & 6 & & & & 6 & 7 & 9 & 4 & 1 & & 6 & & 3 & \\
\hline \multicolumn{21}{|c|}{ Friendship clusters } \\
\hline $\begin{array}{l}\text { Men } \\
\text { FM01 }\end{array}$ & 5 & & & & & & & & & & & 5 & & & & & & & & \\
\hline FM02 & 12 & & & & 1 & 1 & 4 & & & 1 & & & & & & & & 2 & 3 & \\
\hline FM04 & 7 & & & & & & & 3 & & & 2 & & & & & & & & 1 & 1 \\
\hline FM05 & 5 & & & 1 & & 1 & 1 & & & & & & & & & & 1 & 1 & & \\
\hline FM06 & 5 & & & & & & & & & & & & & 5 & & & & & & \\
\hline FM07 & 4 & & & & & & & & & & & & 1 & & & & 3 & & & \\
\hline FM08 & 7 & & & 1 & & & 1 & & & & & & & & & & & & 3 & 2 \\
\hline FM13 & 7 & & & 5 & & 2 & & & & & & & & & & & & & & \\
\hline FM14 & 6 & & & & & & & 1 & & & & 1 & & & & 2 & 2 & & & \\
\hline Total & 58 & & & 7 & 1 & 4 & 6 & 4 & & 1 & 2 & 6 & 1 & 5 & & 2 & 6 & 3 & 7 & 3 \\
\hline \multicolumn{21}{|l|}{ Women } \\
\hline FW02 & 8 & & 1 & & & 1 & 3 & & & 1 & & & & & & 1 & & 1 & & \\
\hline FW03 & 7 & 1 & & & & & & & & & & 6 & & & & & & & & \\
\hline FW05 & 4 & & & 1 & & & 1 & & 1 & & & & & & & 1 & & & & \\
\hline FW08 & 12 & & & & & & & & & & 1 & & 3 & & & & 3 & 4 & 1 & \\
\hline FW15 & 4 & & & & & & & & & & 2 & & & & 2 & & & & & \\
\hline FW17 & 5 & & & 1 & & & & & & & & & & & & 2 & 1 & 1 & & \\
\hline Total & 40 & 1 & 1 & 2 & 0 & 1 & 4 & & 1 & 1 & 3 & 6 & 3 & & 2 & 4 & 4 & 6 & 1 & \\
\hline
\end{tabular}

Fig. 5. Migration network displaying nine main connected components. Each color represent a different segment of lineage (agnatic group). Large nodes represent interviewees, squares represent women, and circles men. Note: for noninterviewees, the default shape is a circle when the gender is unknown.

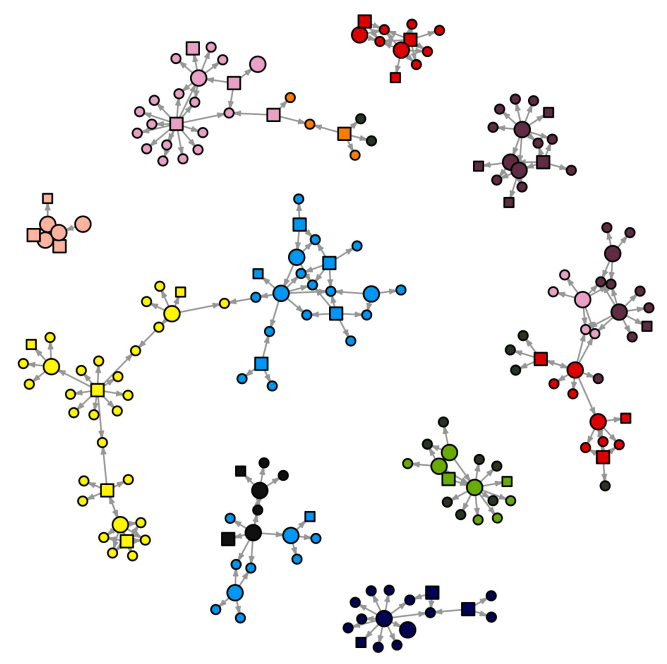

Variations of knowledge across network clusters

There were important differences in the three PERMANOVA analyses conducted for (1) migration, (2) male, and (3) female friendship clusters (Tables 4, 5, and 6). First, we observed quite high $\mathrm{R}^{2}$ values associated with migration clusters, ranging from 0.15472 to 0.19299 in the four domains of TEK, as compared to $\mathrm{R}^{2}$ values associated to other characteristics, which were much smaller (Table 4). In three domains (TEK soils, tado, and botany), these $\mathrm{R}^{2}$ values were associated with significant $\mathrm{p}$-values $(\mathrm{p}<0.01$ or $\mathrm{p}<0.05$ ), showing that differences between migration groups were important enough to explain a fair amount of the overall measured variations in these TEK domains. The agnatic groups (variable segments) also explain a part of the measured variation in the TEK soils $\left(\mathrm{R}^{2}=0.10410, \mathrm{p}<0.05\right)$ and the TEK tado $\left(\mathrm{R}^{2}\right.$ $=0.12342, \mathrm{p}<0.01)$ domains, a result similar to our earlier findings, where the same variable explained $11 \%$ of the variations in these two domains while being the variable of interest (See Salpeteur et al. 2015). Other factors were also shown to significantly affect variations in the TEK botany domain, although less importantly. These factors included the level of schooling $\left(\mathrm{R}^{2}=0.03479, \mathrm{p}<0.05\right)$ and the time elapsed since the pastoral activity has been left $\left(\mathrm{R}^{2}=0.09290, \mathrm{p}<0.01\right)$. 
Table 4. Results from the sequential multivariate Anova (PERMANOVA) applied to migration clusters and selected variables. TEK, traditional ecological knowledge.

\begin{tabular}{lllll}
\hline \hline & TEK & TEK & TEK & TEK \\
breeds & soils & tado & botany \\
& $R^{2}$ value & $R^{2}$ value & $R^{2}$ value & $R^{2}$ value \\
\hline Migration groups & 0.15472 & $0.16419 * *$ & $0.19299 * *$ & $0.19291 *$ \\
Segments & 0.09361 & $0.10410 *$ & $0.12342 * *$ & 0.09044 \\
Gender & 0.02332 & 0.01845 & 0.02212 & \\
Age & 0.05835 & & 0.05350 & \\
Schooling & & & & $0.03479 *$ \\
Occup change delay & & 0.05861 & & $0.09290 * *$ \\
*p $<0.05, * * \mathrm{p}<0.01$ & & & & \\
\hline
\end{tabular}

Second, similar trends can be observed regarding the male friendship network (Table 5): $\mathrm{R}^{2}$ values associated with friendship clusters were quite high (from 0.14917 to 0.17089 ). Besides, $\mathrm{R}^{2}$ values associated with agnatic groups (segments) were also high (from 0.20455 to 0.23666 ). However, in this case, the $\mathrm{R}^{2}$ values were significant only for the TEK soils domain, if we considered the variable associated to friendship clusters $(p<0.01)$. For the same TEK soils domain, the significance level associated with the variables that capture kinship groups and age were insufficient to draw any conclusion $(p<0.1)$. We observed a similar pattern regarding the female friendship network (Table 6) with high $\mathrm{R}^{2}$ values associated to friendship clusters and agnatic groups variables, although none of these results was statistically significant.

Table 5. Results from the sequential multivariate Anova applied to male friendship clusters and other variables. TEK, traditional ecological knowledge.

\begin{tabular}{lllll}
\hline \hline & TEK & TEK & TEK & TEK \\
& $\begin{array}{l}\text { breeds } \\
R^{2} \text { value }\end{array}$ & $\begin{array}{l}\text { soils } \\
R^{2} \text { value }\end{array}$ & $\begin{array}{l}R^{2} \text { value } \\
\text { botany } \\
R^{2} \text { value }\end{array}$ \\
\hline Friendship clusters & 0.15284 & $0.17089 * *$ & 0.16344 & 0.14917 \\
Segments & 0.20455 & 0.23666 & 0.20721 & 0.23250 \\
Age & 0.02769 & 0.06010 & 0.05131 & 0.05373 \\
Schooling & & & & \\
Occup change delay & 0.05093 & 0.04537 & 0.07000 & 0.06028 \\
\hline$* * \mathrm{p}<0.01$ & & & &
\end{tabular}

The high $\mathrm{R}^{2}$ values found for the first variables (migration and friendship clusters) partly resulted from the fact that the PERMANOVA is sequential, and as such the first factor tends to absorb part of the variation that could be attributed to the interaction of this first variable with other variables. However, the significant $\mathrm{p}$-values show that each of the considered variables explains an important part of the overall TEK variations measured.

\section{DISCUSSION}

Informal networks among the Rabari

Our results suggest that the creation of migration collectives and of friendship relations follow varying logics. First, the very high modularity of the migration network shows that, among the Mindiyala Rabari community, migration collectives tend to be clearly distinct from one another. According to our informants, people usually stay in the same migration group for long periods of time, often more than a decade, only changing group in case of strong disagreement with their fellow shepherds. The social network data clearly echoes the discourse of our informants, as the absence of bridging ties between these groups suggests that individuals are connected, in relation to migration, with a restricted set of individuals. Although our inference is clearly limited by the fact that we rely on incomplete network data, the difference of this pattern from the pattern observed in the male friendship network, which is based on the same sample of individuals, suggests that ours is a plausible argument. A similar pattern emerges from the female friendship network, although the higher connectivity of the male friendship network and the higher number of citations per interviewees among males suggest that, among the Rabari, men build friendship ties across a much more extended range of individuals than women. Such contrast may also be the result of gendered difference in perceptions of what a "good friend" is, or in the culturally normative public expression of friendship, a possibility we are unable to precise further at this stage.

Table 6. Results from the sequential multivariate Anova applied to female friendship clusters and other variables. TEK, traditional ecological knowledge.

\begin{tabular}{lllll}
\hline \hline & TEK & TEK & TEK & TEK \\
& breeds & soils & tado & botany \\
& $R^{2}$ value & $R^{2}$ value & $R^{2}$ value & $R^{2}$ value \\
\hline Friendship clusters & 0.14698 & 0.14338 & 0.13857 & 0.17434 \\
Segments & 0.28307 & 0.34274 & 0.39054 & 0.35205 \\
Age & 0.05071 & 0.05647 & 0.06449 & \\
Schooling & & & & \\
Occup change delay & & & & 0.10358 \\
\hline
\end{tabular}

Second, migration groups gather individuals pertaining to varying age groups and education levels, a result that confirms our previous field observations because several generations of people usually migrate together: two brothers and their sons, and the like. Notwithstanding, the age diversity observed across friendship groups is quite surprising and shows that individuals build strong friendship relations not only within their age-mates (as shown by the group FM14), but also with older and younger individuals. This suggests that the notion of friendship within the Rabari community has a stronger vertical component than the notion of friendship in western societies (Allan 1989, Bellotti 2008).

Besides these results, the strong overlap between patrilineal descent groups and migration clusters show that individuals mostly migrate with kin relatives, a result which was expected (Salpeteur et al. 2015). The overlap between friendship and kinship is particularly interesting because it shows that individuals preferentially choose their friends among members of their own segment of lineage, and not outside. Because in Mindiyala people live around a large number of close and distant kin, the chance that they choose friends among kin-related individuals is quite high. But our results show that this preference remains within the 
segment of lineage, which highlights the specific importance of this kin level. Altogether, these results show that patrilineal descent constitutes a privileged basis to build informal relationships within this community.

\section{TEK variations across networks}

Overall, our results provide different insights on the role of the selected variables on variations across the four TEK domains. If some individual variables, i.e., level of education and time spanned since the abandonment of the pastoral activity, lightly affect variations in the TEK botanical domain, the more significant results are related to informal networks and patrilineal descent groups. First, our results show that differences between the studied migration groups in three TEK domains (TEK soils, tado, and botany) are important enough to significantly explain from $16 \%$ to $19 \%$ of the overall variations in these domains. In other words, individuals belonging to the same migration collective tend to hold more homogeneous knowledge, which significantly vary from one group to another. Migration groups within the Rabari community are indeed long-standing collectives within which individuals interact repeatedly, share common experiences, exchange information, and jointly perform the pastoral activity. Our results suggest that these close interactions result in shaping diverging bodies of knowledge.

The almost absence of significant results in the case of male friendship clusters suggests that these collectives are not involved in transmission of TEK in the studied domains, apart from the TEK soils domain. Because the characteristics of soils are of interest not only to migrating pastoralists but also to sedentary pastoralists and other occupations such as farming or land brokering, we can hypothesize that such knowledge is more easily exchanged between male friends, through discussions. A noticeable result is the absence of differences between female friendship clusters, despite a comparable sample size, which suggests that, in each of the four TEK domains, groups of close female friends tend to hold generalistic bodies of knowledge that are not different enough from each other. A possible explanation of this absence of significant variations between either friend groups or segments of lineages, is that in the Dhebar Rabari community, the kinship system is patrilineal and patrilocal (Srivastava 1991, Salpeteur et al. 2015), meaning that women settle in their husband's village and are included in their husband's segment of lineage. Hence, women included in a similar segment or friends cluster actually come from a variety of areas-villages belonging to the same paragana in most cases, and from approximately 2 to 50 kilometers away-for which they often do not share a long common experience with their kin relatives or friends. As a result, within a specific women's cluster there is less homogeneity, and contrasted differences between clusters are not strong enough to explain any of the overall TEK variations.

\section{Going back to the research question}

We started by discussing how social organization may shape the patterns of interindividual exchanges of TEK, by hindering or favoring certain relationships. Our results suggest that in the case of the Rabari community from Mindiyala, the social organization related to migration indeed shapes the distribution of TEK related to the pastoral activity by favoring its transmission within migration groups and hindering its transmission between migrating groups. We have also shown that another type of informal organizations, and specifically friendship networks, do not seem to be involved in the transmission of TEK in most of the chosen domains. These differences may be due to the types of interactions that each of these informal relationships entails: although migration groups involve repeated exchanges, common experiences, and a jointly performed activity, friendship entails mutual help, less frequent exchanges, and does not involve any common practice. Hence the exchanges between friends, which are mostly verbal, might concern mostly theoretical knowledge, whereas exchanges between members of a migration group might concern both theoretical and practical knowledge. Our results suggest that in the case of the four selected TEK domains, the latter form of interaction, i.e., migration, is significantly shaping TEK transmission.

We have also seen that agnatic relations appear as a determining frame for underlying these two types of informal relationships: both migration and friendship tend to happen preferentially within the agnatic group, in our case the segment of lineage, although with a stronger shaping effect in the case of migration groups. This finding brings further insights in relation to the potential role of social organization in the transmission of TEK: patrilineal descent groups, which are a corner stone of Rabari social organization, provide the structure that shapes important parts of the collective life and of daily interactions, such as migration groups and friendship. Hence the constitution of common bodies of TEK that result from shared experience tends to happen within kin-based groups. We relate these results to previous studies. For example, a previous study has shown that kinship and friendship relations are the most important when Mexican fishers seek information about the state of the natural resources, particularly in times of scarcity (Ramirez-Sanchez and Pinkerton 2009). This kind of insight shows that such relationships are paramount and that they must be taken into account while studying natural resource governance networks. Our results provide a supplementary insight about the importance of these social relations by showing that they are also playing an important role in shaping TEK distribution, across the studied community of seminomadic pastoralists. This shows the importance of formal and informal social structures that are framing and grounding the daily life of local communities, and, as such, influence the dynamics of constitution and transmission of bodies of TEK. Further research on intra-cultural TEK variations may want to look at these informal relationships that are part of the social organization of local communities, to better understand the dynamics of TEK systems within local communities of resource users.

\section{CONCLUSION}

Previous research has shown that informal networks of actors are likely to play a key role in natural resource governance schemes through easing trust-building or information transmission across a set of diverse actors, institutional and noninstitutional (Bodin et al. 2011). In this study, we show that informal networks, or, said differently, informal social structures, are also likely to shape in a significant way the transmission and distribution of TEK among local actors. Reaching effective governance of natural resources implies a mobilization of the knowledge of multiple resource users, which is important to uncover the dynamics of TEK variations and transmission across local communities. Although informal networks are increasingly taken into account, 
most previous research on the topic has focused on networks explicitly dedicated to exchanges of knowledge about the natural resources. We show here that other networks that are not specifically related to knowledge exchanges or to natural resource management, can also act as strong drivers of TEK transmission across local communities. A better inclusion of such informal networks in future works would increase the understandings of the complex TEK dynamics in fast changing communities.

Responses to this article can be read online at: http://www.ecologyandsociety.org/issues/responses. $\mathrm{php} / 8332$

\section{Acknowledgments:}

This research was conducted within the CONSOLIDER SimulPast project ("Simulating the Past to Understand Human Behaviour," CSD2010-00034), funded by the former Spanish Ministry for Science and Innovation. We thank all inhabitants of Mindiyala and Kutch who helped us and the Marag nongovernmental organization for contact facilitation.

\section{LITERATURE CITED}

Agrawal, A. 1992. The grass is greener on the other side: a study of Raikas, migrant pastoralists of Rajasthan. International Institute of Environment and Development, London, UK.

Allan, G. A. 1989. Friendship: developing a sociological perspective. Harvester Wheatsheaf. Hemel Hempstead, UK.

Armitage, D. R., R. Plummer, F. Berkes, R. I. Arthur, A. T. Charles, I. J. Davidson-Hunt, A. P. Diduck, N. C. Doubleday, D. S. Johnson, M. Marschke, P. McConney, E. W. Pinkerton, and E. K. Wollenberg. 2008. Adaptive co-management for socialecological complexity. Frontiers in Ecology and the Environment 7(2):95-102. http://dx.doi.org/10.1890/070089

Aswani, S. 2002. Assessing the effects of changing demographic and consumption patterns on sea tenure regimes in the Roviana Lagoon, Solomon Islands. AMBIO: A Journal of the Human Environment 31(4):272-284. http://dx.doi.org/10.1579/0044-7447-31.4.272

Barth, F. 2002. An anthropology of knowledge. Current Anthropology 43(1):1-18. http://dx.doi.org/10.1086/324131

Begossi, A., N. Hanazaki, and J. Y. Tamashiro. 2002. Medicinal plants in the Atlantic Forest (Brazil): knowledge, use, and conservation. Human Ecology 30(3):281-299. http://dx.doi. org/10.1023/A:1016564217719

Bellotti, E. 2008. What are friends for? Elective communities of single people. Social Networks 30(4):318-329. http://dx.doi. org/10.1016/j.socnet.2008.07.001

Berkes, F., J. Colding, and C. Folke. 2000. Rediscovery of traditional ecological knowledge as adaptive management. Ecological Applications 10(5):1251-1262. http://dx.doi. org/10.1890/1051-0761(2000)010[1251:roteka]2.0.co;2

Berkes, F., and N. J. Turner. 2006. Knowledge, learning and the evolution of conservation practice for social-ecological system resilience. Human Ecology 34(4):479-494. http://dx.doi. org/10.1007/s10745-006-9008-2

Bernard, H. R. 2006. Research methods in anthropology: qualitative and quantitative approaches. Fourth edition. Altamira Press, Walnut Creek, California, USA.

Bharwada, C., and V. Mahajan. 2010. Mangrove, markets and migration. Camel pastoralists and conservation in the Gulf of Kutch, Gujarat. Pages 29-53 in Case studies of livestock environment interface experiences. LEAD Advocacy Network Project, Gujarat State. Centre for Environment Education, Ahmedabad, India.

Bodin, Ö., S. Ramirez-Sanchez, H. Ernstson, and C. Prell. 2011. A social relational approach to natural resource governance. Pages 3-28 in Ö. Bodin and C. Prell, editors. Social networks and natural resource management. Uncovering the social fabric of environmental governance. Cambridge University Press, New York, New York, USA. http://dx.doi.org/10.1017/cbo9780511894985.002

Boster, J. S. 1986. Exchange of varieties and information between Aguaruna manioc cultivators. American Anthropologist 88 (2):428-436. http://dx.doi.org/10.1525/aa.1986.88.2.02a00100

Calvet-Mir, L., M. Calvet-Mir, J. Luis Molina, and V. ReyesGarcía. 2012. Seed exchange as an agrobiodiversity conservation mechanism. A case study in Vall Fosca, Catalan Pyrenees, Iberian Peninsula. Ecology and Society 17(1):29. http://dx.doi. org/10.5751/ES-04682-170129

Camou-Guerrero, A., V. Reyes-García, M. Martínez-Ramos, and A. Casas. 2008. Knowledge and use value of plant species in a Rarámuri community: a gender perspective for conservation. Human Ecology 36(2):259-272. http://dx.doi.org/10.1007/ s10745-007-9152-3

Choksi, A., and C. Dyer. 1996. Pastoralism in a changing world: patterns of adaptation among the Rabaris of Kutch, Gujarat. International Institute of Environment and Development, London, UK.

Crona, B., and Ö. Bodin. 2006. What you know is who you know? Communication patterns among resource users as a prerequisite for co-management. Ecology and Society 11(2):7. [online] URL: http://www.ecologyandsociety.org/vol11/iss2/art7/

Crona, B., and Ö. Bodin. 2011. Friends or neighbors? Subgroup heterogeneity and the importance of bonding and bridging ties in natural resource governance. Pages 206-233 in Ö. Bodin and C. Prell, editors. Social networks and natural resource management. Uncovering the social fabric of environmental governance. Cambridge University Press, New York, New York, USA. http:// dx.doi.org/10.1017/cbo9780511894985.010

Csardi, G., and T. Nepusz. 2006. The igraph software package for complex network research. Inter Journal Complex Systems 1695.

Dray, S., and A.-B. Dufour. 2007. The ade4 package: implementing the duality diagram for ecologists. Journal of Statistical Software 22(4):1-20. http://dx.doi.org/10.18637/jss. v022.i04

Dyer, C. 2008. Literacies and discourses of development among the Rabaris of Kutch, India. Journal of Development Studies 44 (6):863-879. http://dx.doi.org/10.1080/00220380802058222 
Gadgil, M., F. Berkes, and C. Folke. 1993. Indigenous knowledge for biodiversity conservation. Ambio 22(2/3):151-156.

Geerlings, E. 2001. Sheep husbandry and ethnoveterinary knowledge of Raika sheep pastoralists in Rajasthan, India. Thesis, Wageningen University, Wageningen, The Netherlands.

Ghimire, S. K., D. McKey, and Y. Aumeeruddy-Thomas. 2005. Heterogeneity in ethnoecological knowledge and management of medicinal plants in the Himalayas of Nepal: implications for conservation. Ecology and Society 9(3):6.

Girvan, M., and M. E. J. Newman. 2002. Community structure in social and biological networks. Proceedings of the National Academy of Sciences 99(12):7821-7826. http://dx.doi.org/10.1073/ pnas. 122653799

Holling, C. S. 1973. Resilience and stability of ecological systems. Annual Review of Ecology and Systematics 4:1-23. http://dx.doi. org/10.1146/annurev.es.04.110173.000245

Hopkins, A. 2011. Use of network centrality measures to explain individual levels of herbal remedy cultural competence among the Yucatec Maya in Tabi, Mexico. Field Methods 23(3):307-328. http://dx.doi.org/10.1177/1525822x11399400

Joshi, S., W. A. Jasra, M. Ismail, R. M. Shrestha, S. L. Yi, and N. Wu. 2013. Herders' perceptions of and responses to climate change in northern Pakistan. Environmental Management 52 (3):639-648. http://dx.doi.org/10.1007/s00267-013-0062-4

Labeyrie, V., B. Rono, and C. Leclerc. 2014. How social organization shapes crop diversity: an ecological anthropology approach among Tharaka farmers of Mount Kenya. Agriculture and Human Values 31(1):97-107. http://dx.doi.org/10.1007/ s10460-013-9451-9

Leclerc, C., and G. Coppens d'Eeckenbrugge. 2011. Social organization of crop genetic diversity. The $\mathrm{G} \times \mathrm{E} \times \mathrm{S}$ interaction model. Diversity 4(1):1-32. http://dx.doi.org/10.3390/d4010001

Marin, A. 2010. Riders under storms: contributions of nomadic herders' observations to analysing climate change in Mongolia. Global Environmental Change 20(1):162-176. http://dx.doi. org/10.1016/j.gloenvcha.2009.10.004

Mauss, M. 1979. Seasonal variations of the Eskimo: a study in socialmorphology. (J. J. Fox, translator). Routledge \& Kegan Paul, London, UK.

Ohmagari, K., and F. Berkes. 1997. Transmission of indigenous knowledge and bush skills among the Western James Bay Cree women of subarctic Canada. Human Ecology 25(2):197-222. http://dx.doi.org/10.1023/A:1021922105740

Oksanen, J., F. G. Blanchet, R. Kindt, P. Legendre, P. R. Minchin, R. B. O'Hara, G. L. Simpson, P. Solymos, H. H. Stevens, and H. Wagner. 2013. Vegan: community ecology package, v2.0-10.

Prévot, S. 2007. Les nomades d'aujourd'hui. Ethnologie des éleveurs Raika en Inde. Aux lieux d'être, Montreuil, France.

R Development Core Team. 2011. R: A language and environment for statistical computing. R Foundation for Statistical Computing, Vienna, Austria.
Ramirez-Sanchez, S., and E. Pinkerton. 2009. The impact of resource scarcity on bonding and bridging social capital: the case of fishers' information-sharing networks in Loreto, BCS, Mexico. Ecology and Society 14(1):22. [online] URL: http://www. ecologyandsociety.org/vol14/iss1/art22/

Reyes-García, V., N. Marti, T. McDade, S. Tanner, and V. Vadez. 2007. Concepts and methods in studies measuring individual ethnobotanical knowledge. Journal of Ethnobiology 27 (2):182-203. http://dx.doi.org/10.2993/0278-0771(2007)27[182: camism]2.0.co;2

Reyes-García, V., J. L. Molina, L. Calvet-Mir, L. Aceituno-Mata, J. J. Lastra, R. Ontillera, M. Parada, M. Pardo-de-Santayana, M. Rigat, J. Vallès, and T. Garnatje. 2013. "Tertius gaudens": germplasm exchange networks and agroecological knowledge among home gardeners in the Iberian Peninsula. Journal of Ethnobiology and Ethnomedicine 9:53. http://dx.doi. org/10.1186/1746-4269-9-53

Reyes-García, V., V. Vadez, E. Byron, L. Apaza, W. R. Leonard, E. Perez, and D. Wilkie. 2005. Market economy and the loss of folk knowledge of plant uses: estimates from the Tsimane' of Bolivian Amazon. Current Anthropology 46(4):651-656. http:// dx.doi.org/10.1086/432777

Salpeteur, M., M. Madella, H. Patel, and V. Reyes-García. 2016. Adaptation, access to resources and mobility: from contemporary pastoral systems to ancient societies. Nomadic Peoples, in press.

Salpeteur, M., H. Patel, A. L. Balbo, X. Rubio-Campillo, M. Madella, P. Ajithprasad, and V. Reyes-García. 2015. When knowledge follows blood. Kin groups and the distribution of traditional ecological knowledge in a community of seminomadic pastoralists, Gujarat (India). Current Anthropology 56 (3):471-483. http://dx.doi.org/10.1086/681006

Singh, D., S. Kachhawaha, M. K. Choudhary, M. L. Meena, and P. K. Tomar. 2014. Ethnoveterinary knowledge of Raikas of Marwar for nomadic pastoralism. Indian Journal of Traditional Knowledge 13(1):123-131.

Smith, M., N. Milic-Frayling, B. Shneiderman, E. Mendes Rodrigues, J. Leskovec, and C. Dunne. 2010. NodeXL: a free and open network overview, discovery and exploration add-in for Excel 2007/2010. Social Media Research Foundation.

Srivastava, V. 1991. Who are the Raikas/Rabaris? Man in India 71(1):279-304.

Zarger, R. 2002. Acquisition and transmission of subsistence knowledge by Q'eqchi'Maya in Belize. Pages 593-603 in J. Stepp, F. Wyndhamand, and R. Zarger, editors. Ethnobiology and biocultural diversity. University of Georgia Press, Athens, Georgia, USA. 